Bristol-Myers Squibb, Celgene Corporation, Janssen Biotech, JanssenOrtho Inc., LEO Pharma, Novartis, UCB, Wolf-Henning Boehncke Consultant for: Pfizer Inc, Speakers bureau: Pfizer Inc, Xie L Xu Employee of: Employee of Janssen Research \& Development, LLC, Chenglong Han Employee of: Employee of Janssen Research \& Development, LLC DOI: 10.1136/annrheumdis-2019-eular.172

\section{AB0746 WORKING STATUS AND FACTORS ASSOCIATED WITH WORK PRODUCTIVITY AMONG PEOPLE WITH PSORIATIC ARTHRITIS}

Didem Erdem, Halise Hande Gezer, Sevtap Acer Kasman, Mehmet Tuncay Duruöz. Marmara University Faculty of Medicine, Department of Physical Medicine and Rehabilitation, Rheumatology Division, Istanbul, Turkey

Background: Work disability is an important functional outcome measure in psoriatic arthritis (PsA) and includes unemployment and loss of work productivity.

Objectives: The aim of this study is to investigate the working status and the factors associated with work productivity in patients with PsA.

Methods: Patients with PsA according to Classification Criteria for Psoriatic Arthritis (CASPAR) were included in the study consecutively, without sample selection. Data about age, sex, disease duration (month) were noted. Disease activity was assessed with DAPSA (Disease Activity in Psoriatic Arthritis) and BASDAI (Bath Ankylosing Spondylitis Disease Activity Index). The Health Assessment Questionnaire (HAQ) was used to evaluate physical disability. The Psoriatic Arthritis Quality of Life (PsAQoL) scale was used to assess the quality of life. Fatigue and stiffness were assessed on the Visual Analogue Scale (VAS). Anxiety and depression were evaluated with HAD (Hospital Anxiety and Depression) scale.

Assessing work disability, we asked some questions to the patients including employment status, and early retirement, changing or reducing work due to PSA. We used WPAI: PsA (Work Productivity and Activity Impairment Questionnaire) to evaluate the impact of PsA on work productivity. WPAI: PSA consists of six questions and gives four scores: the percentage of absenteeism (work time missed due to PsA), the percentage of presenteeism (reduced productivity at work due to PsA), an overall work impairment (combines absenteeism and presenteeism) and percentage of impairment in daily activities.

The association between WPAl: PsA scores and HAQ, PsAQoL, HAD, fatigue and stiffness was determined by Spearman's correlation coefficient. The Mann Whitney-U test was used to compare the means of groups. The descriptive analysis was done for demographic data. $\mathrm{P}<0.05$ accepted as significant. SPSS 20.0 (Statistical package for social sciences for Windows 20.0) program was used for the statistical analysis.

Results: The mean age of 60 patients (38 female, 22 male) with PsA was 48.13 (SD: 11.53) years. The median (min-max) duration of disease was 36 (3-384) months.

$63.33 \%$ of the patients were not working and $57.89 \%$ of these patients were housewives, and $23.68 \%$ were retired. $11.66 \%$ of the patients with PsA were unemployed. There were no patients who were retired early due to the disease. Percentage of the stopping work, changing work or reducing working hours due to PsA was $3.3 \%, 6.7 \%$ and $10 \%$, respectively.

There was no significant difference between the working and not-working groups of patients according to the disease duration, DAPSA, BASDAi and $H A Q$ scores $(p>0.05)$. The mean age was higher in the non-working group $(\mathrm{p}<0.005)$.

There was no absenteeism in $63.3 \%$ of patients. The mean percentage of the presenteeism was 36 (SD: 30.79) and the mean percentage of the overall work impairment was 41 (SD: 34.06 ). There were no significant correlations between WPAI: PsA scores and age, disease duration, DAPSA score $(p>0.05)$. Presenteeism and overall work impairment had significant moderate correlations with fatigue (rho: $0.639, p: 0.001$; rho: 0.607 , p: 0.003), morning stiffness (rho: 0.424 , p: 0.049 ; rho: 0.484 , p: 0.023), HAQ (rho: 0.532, p: 0.011; rho: 0.551 , p: 0.008), PsAQoL (rho: 0.481 , p: 0.023 ; rho: $0.510, \mathrm{p}: 0.015$ ), HAD depression (rho: 0.650 , p: 0.001 ; rho: $0.634, \mathrm{p}: 0.002$ ), and HAD anxiety scores (rho: 0.486 , p: 0.022 ; rho: $0.527, \mathrm{p}: 0.012$ ), respectively.

Conclusion: Psoriatic arthritis can cause loss of work productivity. The severity of work impairment is associated with fatigue, stiffness, physical disability, depression, anxiety and health-related quality of life. In our study population, the percentage of housewives and retired was high and the rate of unemployment was $11.66 \%$. This is a preliminary study and will continue in larger patient populations.

Disclosure of Interests: Didem Erdem: None declared, Halise Hande Gezer: None declared, Sevtap Acer Kasman: None declared, Mehmet
Tuncay Duruöz Grant/research support from: Abvie, Speakers bureau: Novartis, AMGEN, Abdi İbrahim, Illko

DOI: 10.1136/annrheumdis-2019-eular.6190

\section{AB0747 RESPONSE TO SECUKINUMAB AMONG NAIVE AND BIOLOGICALLY EXPERIENCED PATIENTSIN PSORIATIC ARTHRITIS}

Shehla Farrukh, Ann O. Riordan, Muhammad Haroon, Fahd Adeeb. University Hospital Kerry, rheumatology, tralee, Ireland

Background: Secukinumab is a recombinant human monoclonal immunoglobulin IgG antibody that selectively targets IL-17A and blocks its interaction with the IL-17 receptor. Inhibition of the downstream effects of this proinflammatory cytokine thereby interferes with key psoriasis disease pathways while promoting normalization of immune function and skin histology.

Objectives: The aim of the study was two-fold; firstly, to compare the response to Secukinumab in psoriatic arthritis (PsA) patients who were biologically naive and experienced, and secondly to compare the response between smokers and non-smokers.

Methods: In collaboration with the National Psoriatic Arthritis Registry of Ireland, patients who were diagnosed and treated as PsA at University Hospital Kerry between March 2017 and October 2018 were included in this population-based cohort study.Patients demographic, clinical characteristics, treatment strategies (including response rates and adverse effects) were captured at baseline and at follow-up outpatient visits.

Results: A total of 96 patients were identified and included in the study (mean age of 56.6 years; male to female ratio of $1: 1,49$ males, 47 females). Of these patients, 15 received Secukinumab (7 biologically-naive patients, 8 patients with previous treatment failure to anti-TNF agents (3 patients received one anti-TNF, 5 received two different anti-TNFs). In the biologically-naive group, 5 patients $(71 \%)$ had completeresponse to Secukinumab, one patient (14.3\%) had complete improvement of joint symptoms but remained fatigued (high BRAF score) while 1 patient (14.3\%) had no improvement. All 7 of these patients were exposed to cigarette smoking (6 current smokers, one ex-smoker). In patients who previously failed anti-TNF, five(62.5\%) remained symptomatic (tender \& swollen joints, PROMs and BRAF score remained high) despite treatment with Secukinumab. Only three patients $(37.5 \%)$ responded well to treat ment. Two of the eight patients never smoked (both did not respond to Secukinumab) while the other 6 patients $(3$ responded, 3 had no response) were ex-smokers.

Conclusion: In our study, Secukinumab demonstrated better response to the biologically-naive PsA patients, while smoking did not increase the risk of disease activity among PsA patients receiving Secukinumab.

Disclosure of Interests: None declared

DOI: 10.1136/annrheumdis-2019-eular.3842

\section{AB0748 EVOLUTION ON HEALTH-RELATED QUALITY OF LIFE IN PSORIATIC ARTHRITIS PATIENTS}

Dalifer Freites Nuñez ${ }^{1,2}$, Leticia León ${ }^{2}$, Judit Font ${ }^{1}$, Alfredo Madrid García ${ }^{2}$, Zulema Rosales ${ }^{1}$, Lydia Abasolo $^{1,2}$, Benjamin Fernandez ${ }^{1}$, Luis

Rodriguez Rodriguez ${ }^{1,2} .{ }^{1}$ Hospital Clínico San Carlos, Rheumatology, Madrid, Spain; ${ }^{2}$ Instituto de Investigación Sanitaria San Carlos, Rheumatology, Madrid, Spain

Background: Psoriatic arthritis (PsA) is a chronic, progressive and inflammatory arthritis. It is consider a multifaceted disease, with a high impact on patient's psychological and physical well-being, with patients reporting lower health-related quality of life (HRQoL). Data of burden of disease is substantial and even though there are some studies that identify risk factors with longstanding PsA, there exists a need for properly designed studies to learn more about the evolution of HRQoL throughout the follow-up in this condition.

Objectives: To analyze the evolution on HRQoL in patients with PsA and to to evaluate factors that may influence this evolution.

Methods: Retrospective longitudinal observational study including incident patients diagnosed with PSA from 2007 to 2016, and followed-up unti loss of follow-up or December 2017; with at least two registered visits; having received any ICD9/ICD10 diagnosis code of PsA; and with symptoms onset after 16 years of age. Patients were collected from the rheumatology outpatient clinic of a tertiary hospital (Hospital Clínico San Carlos, Madrid, Spain). Clinical information was collected from a departmental electronic health record, including demographic, clinical, comorbidities, treatment, and HRQoL related variables (measured with the Rosse 
Classification Index). The influence of these variables in repeated measures of HRQoL was analysed using bivariate and multivariate generalized estimating equations (GEE) models nested by patient. Those variables with a p-value $<0.20$ (plus age, gender, follow-up time, and calendar year of diagnosis) were introduced in the multivariate analysis. Bonferroni p-value threshold adjustment was carried out.

Results: We included 187 patients, with a median follow-up of 3.6 years (interquarltile range: 0.8 to 6.3 ). $48 \%$ were women, with a median age at the onset of symptoms and diagnosis of 45 and 49 years, respectively. $86 \%$ of patients had a personal history of Psoriasis. Regarding clinical manifestations during the follow-up, $83 \%, 30 \%, 26 \%$, and $22 \%$ of the patients presented with peripheral arthritis, inflammatory low back pain, enthesitis and dactylitis, respectively. In addition, they received treatment with nonsteroidal antiinflammatory medications (NSAIDs), oral glucocorticoids and disease-modifying antirheumatic drugs (DMARDs) $71 \%, 52 \%$ and $82 \%$, respectively. $20 \%$ received biological agents. The Rosser median value at the first visit was 0.986 , with an slight increase alter the first 2 years and a decline after 5 years of follow-up (Figure 1).

With respect to the variables independently associated with $\mathrm{HRQOL}$ during follow-up, the history of osteoporotic fractures $(p=8.1 \times 10-18)$ and chronic obstructive pulmonary disease $(p=5.0 \times 10-8)$ were associated with a poorer quality of life. Conversely, treatment with methotrexate $(p=6.4 \times 10-5)$, and the use of bone-forming agents $(p=7.8 \times 10-4)$ were associated with better HRQoL. History of osteoporosis and use of biphosphonates and denosumab were also associated with HRQoL, although not significantly after p-value adjustment.

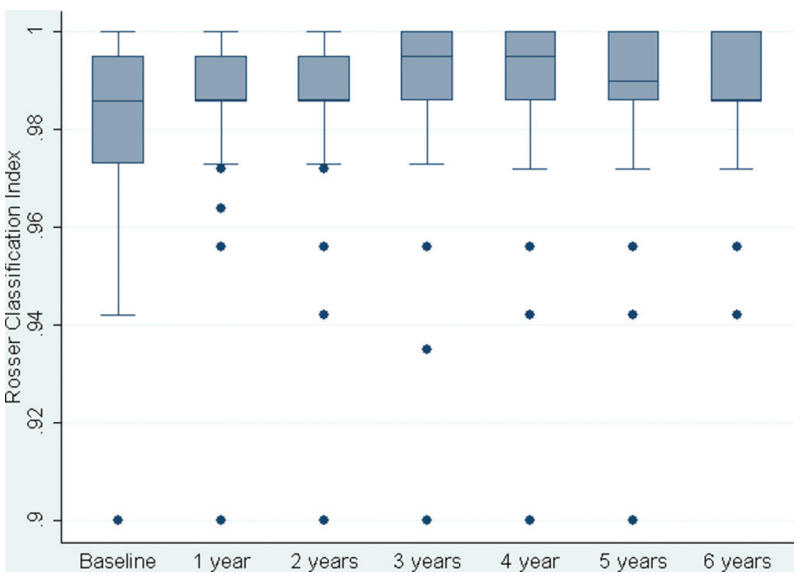

Conclusion: We have identified different factors associated with $\mathrm{HRQ}$ during the evolution of patients with PsA. We observed that the presence of certain comorbidities were independently associated with a worse HRQoL. In addition, regarding different treatments, the use of methotrexate and bone-forming agents were independently associated with a better HRQoL.

Disclosure of Interests: None declared

DOI: 10.1136/annrheumdis-2019-eular.7206

\section{\begin{tabular}{|l|l}
\hline AB0749 & ARE THERE ANY DIFFERENCES IN THE EFFECTIVITY
\end{tabular} AND SAFETY OF CERTOLIZUMAB PEGOL IN PATIENTS WITH PSORIATIC ARTHRITIS ACCORDING THEIR GENDER?}

Rosa García ${ }^{1}$, Manuel Fernandez-Prada ${ }^{2}$, Arantxa Conesa $^{3}$, Jose Campos Esteban ${ }^{4}$, Ana Urruticoechea-Arana ${ }^{5}$, Alejandro Olive ${ }^{6}$, Silvia Paredes ${ }^{7}$ Delia Taverner ${ }^{7}$, Carlos Gonzalez ${ }^{8}$, RENACER. ${ }^{1}$ Hospital Virgen de la Victoria, Rheumatology, Málaga, Spain; ${ }^{2}$ Hospital Universitario de Guadalajara, Rheumatology, Guadalajara, Spain; ${ }^{3}$ Hospital General Universitari de Castelló, Rheumatology, Castelló de la Plana, Spain; ${ }^{4}$ Hospital Universitario Puerta de Hierro, Rheumatology, Madrid, Spain; ${ }^{5}$ Hospital Can Misses, Rheumatology, Eivissa, Spain; ${ }^{6}$ Hospital Germans Trias i Pujol, Badalona, Spain; ${ }^{7}$ Hospital Universitari Sant Joan de Reus, Reus, Spain; ${ }^{8}$ Hospital General Universitario Gregorio Marañón, Rheumatology, Madrid, Spain

Background: Gender-related biochemical, hormonal and psychological factors could play an important role in the response to TNF blocker therapy in psoriatic arthritis (PsA). Scarce data are available analyzing differences in effectiveness and safety of the antiTNFs, and none in particular with Certolizumab Pegol (CZP) according to the gender.

Objectives: To evaluate the influence of the gender in the effectiveness and safety of CZP in the routine clinical setting in PSA patients.

Methods: Observational, national and muticentric cohort (approved by loca ethical committee), PsA patients treated with CZP according to routine clinical practice were studied for 12 months. Clinical and disease characteristics and disease activity between gender were compared. Safety analysis: adverse events and withdrawn.

Results: 347 PsA patients were analyzed. No statistical differences were found between women and men at baseline in demographics, clinical variables, except for previous biologic treatment and ESR (Table 1). In both genders, a statistical significant decreased was observed after 1 year of CZP treatment in the following variables: DAS28(CRP); SJC; TJC; PGA (patient global ssesment);\% patients with enthesitis, dactilytis and nail disease; but with no differences between females and males. Variables that influence the response at 12 months are: disease duration, CRP and TJC at baseline. Drug survival of CZP was $80.1 \%$, and no differences were observed in gender. Adverse events related to CZP were observed in $9.5 \%$ and $19.9 \%$ withdrawn treatment: $12.4 \%$ due to lack of effectiveness, $4.0 \%$ due to intolerance and $3.5 \%$ other reasons.

Conclusion: CZP has shown to be effective and safe in PsA patient after a year of treatment in clinical practice regardless patient's gender.

Abstract AB0749 Table 1. Baseline demographic, clinical and disease activity characteristics.

\begin{tabular}{lcc}
\hline Demographic variables & Female & Male \\
\hline Gender, $n(\%)$ & $196(56.5) \mathrm{N}=347$ & $151(43.5) \mathrm{N}=347$ \\
Age, median (min-max), years & $48.5(22.3 ; 81.1) \mathrm{N}=188$ & $50.5(22.0 ; 78.0) \mathrm{N}=137$ \\
No smoking, $\mathrm{n}(\%)$ & $137(79.2) \mathrm{N}=173$ & $79(56.8) \mathrm{N}=139$ \\
Disease characteristics & & \\
Disease duration, mean (Q1-Q3) & $6.5(1.8-8.7) \mathrm{N}=188$ & $6.9(1.2-10.0) \mathrm{N}=137$ \\
Presence of HLAB27 & $28(20.3) \mathrm{N}=138$ & $13(13.0) \mathrm{N}=100$ \\
Previous biologics & $\mathrm{N}=155$ & $\mathrm{~N}=124$ \\
$\cdot 0$ & $37(23.9)$ & $48(38.7)$ \\
$\cdot 1$ & $67(43.2)$ & $42(33.9)$ \\
$\cdot \geq 2$ & $51(32.9)$ & $34(27.4)$
\end{tabular}

Disease activity

TJC (28 joints), mean (Q1-Q3) $7.3(4.0-10.0) \mathrm{N}=167$

SJC (28 joints), mean (Q1-Q3)

$6.5(3.0-8.0) \mathrm{N}=125$

PtGA (VAS), mean (Q1-Q3)

PhGA (VAS), mean (Q1-Q3)

$5.2(2.0-8.0) \mathrm{N}=156$

$4.8(2.0-6.0) \mathrm{N}=116$

$7.0(6.0-8.0) \mathrm{N}=195$

$6.2(5.0-8.0) \mathrm{N}=193$

$6.8(6.0-8.0) \mathrm{N}=150$

$0.1(1.0-14.0) \mathrm{N}=195$

$6.1(5.0-7.0) \mathrm{N}=150$

ESR $(\mathrm{mm} / \mathrm{h})$, mean (Q1-Q3)

$24.8(8.8-37.3) \mathrm{N}=90$

$4(0.9-11.4) \mathrm{N}=151$ $16.6(5.0-21.3) \mathrm{N}=58$

Abstract AB0749 Table 2.. CZP effectiveness at 1 year of treatment

\begin{tabular}{lcccccc}
\hline & \multicolumn{2}{c}{ Basal } & \multicolumn{2}{c}{ 3 months } & \multicolumn{2}{c}{ 12 months } \\
\hline & $\mathbf{F}$ & $\mathbf{M}$ & $\mathbf{F}$ & $\mathbf{M}$ & $\mathbf{F}$ & $\mathbf{M}$ \\
\hline DAS28 (CRP); mean (SD) & 4.7 & 4.5 & 3.9 & 3.9 & 3.7 & 3.4 \\
& $(0.9)$ & $(0.8)$ & $(0.9)$ & $(1.0)$ & $(1.0)$ & $(1.0)$ \\
TJC; mean (SD) & 7.3 & 6.5 & 5.2 & 5.1 & 4.4 & 4.0 \\
& $(5.1)$ & $(4.4)$ & $(4.3)$ & $(4.3)$ & $(4.3)$ & $(4.3)$ \\
SJC; mean (SD) & 5.2 & 4.8 & 3.8 & 3.9 & 3.6 & 3.7 \\
& $(3.8)$ & $(3.5)$ & $(3.1)$ & $(3.3)$ & $(3.1)$ & $(3.4)$ \\
Enthesitis, n (\%) & 38 & $35(25)$ & 30 & 26 & 12 & $8(9.8)$ \\
& $(21.3)$ & & $(16.9)$ & $(18.6)$ & $(9.8)$ & \\
Dactlylitis, n (\%)* & 48 & 48 & 27 & 31 & $7(5.6)$ & 10 \\
& $(26.4)$ & $(34.8)$ & $(14.8)$ & $(22.5)$ & & $(12.5)$ \\
Presence of nail disease, $\mathrm{n}$ & 21 & 28 & 17 & 25 & $5(9.8)$ & 10 \\
& $(24.7)$ & $(38.4)$ & $(20.0)$ & $(34.2)$ & & $(25.0)$ \\
\hline
\end{tabular}

Disclosure of Interests: Rosa García : None declared, Manuel Fernandez Prada: None declared, Arantxa Conesa: None declared, Jose Campos Esteban: None declared, ANA URRUTICOECHEA-ARANA: None declared, Alejandro Olive: None declared, SILVIA PAREDES Speakers bureau: Bristol, Roche, Amgen, Pfiser, Abbvie, lilly, UCB, Delia Taverner Speakers bureau: amgen, pfiser, Bristol, Lilly, Roche, Carlos Gonzalez Consultant for: Celgene, Gilead, Janssen, Merk, Novartis, Pfizer, Speakers bureau: Celgene, Roche, UCB

DOI: 10.1136/annrheumdis-2019-eular.8143 